\title{
Self-Medication Practices with Antibiotics among Second Year Medical Students of Government Medical College, Raigarh, Chhattisgarh
}

\author{
Pramood Kumar Gupta ${ }^{1}$, Presenjit Raut ${ }^{2 *}$ \\ ${ }^{1}$ Associate Professor, Department of Medicine,KGH Hospital, Raigarh-Chhattisgarh, INDIA. \\ ${ }^{2}$ Associate Professor, Department of Pharmacology, GMC, Raigarh-Chhattisgarh, INDIA.
}

\begin{abstract}
Background: Self medication practice especially using antibiotics has tremendously increased in the society that leads to unwanted consequences such as drug resistance. Objective: The objective of this study was to evaluate the self-medication practices with antibiotics among the second year medical students of Government Medical College, Raigarh. Materials \& Methods: It was a questionnaire based descriptive study. A prevalidated questionnaire, which contained both open \& close ended questions were given to the second year medical students. Data were analyzed using Excel sheet \& results were expressed as counts and percentages. Results: Females outnumber males in this study, 27 versus 20. The most common indication for which self-medication was opted was fever with cough and cold. The information about the antibiotic was obtained from a past prescription from a physician. The most common antibiotic that was used by most of students was azithromycin. Conclusion: There was a high level of self-medication with antibiotics in our study, but this high level of self-prescription seen is also having some disadvantages, as improper duration of use might lead to development of resistance.
\end{abstract}

Key words: Self-Medication, Antibiotics, Drug Resistance, Co-Prescription, Azithromycin.

Citation: Gupta PK, Raut P. Self-Medication Practices with Antibiotics among Second Year Medical Students of Government Medical College, Raigarh, Chhattisgarh. Int J Pharmacol and Clin Sci. 2017;6(1):15-19.

\section{INTRODUCTION}

Antibiotics play a crucial role both in life of a doctor as well as the patient. These subset of drugs are not only lifesaving but they also relieves the distress associated with infection. Life without them seems to be quite un-comfortable. Antibiotics are the mainstay of treating infection and hence every effort should be made for their rational use. Self-medication labels to the use of any drug without a valid prescription, or just on the basis of prior knowledge of drug use or any information obtained from any source such as social media, books, journals, internet etc. During recent years, self-medication has tremendously increased in the society as lay person are getting more and more information about the drug use and hence practise of self-medication is increasing day by day.

Self-medication can be defined as the use of drugs to treat self-diagnosed disorders or symptoms, or the intermittent or continued use of a once prescribed drug for chronic or recurrent disease or symptoms. ${ }^{[1,2]}$

Self-medication is possible with any group/category of drug, here in this study we have focussed our attention towards self-medication with only antibiotics and we have seen its prevalence among the II ${ }^{\text {nd }}$ year MBBS students of Late Shri Lakhiram Agrawal Memorial Govt. Medical College which is situated in the district

Received : 20 -3-2017 Revised : 29-3-2017;

Accepted : 30-3-2017

*Correspondence : Dr.Presenjit Raut,

Associate Professor, Department of Pharmacology, GMC,Raigarh-Chhattisgarh, INDIA.

Phone no: 09406393906 / 8319711163

E-mail: presenjit@gmail.com

Conflict of interest: Nil ; Source of support : Nil

Copyright: $\odot 2017$ Journal. All rights reserved.

DOI : $10.5530 /$ ijpcs.6.1.3 
Raigarh of C.G. state. The college was started in the year 2013 with a intake of only 50 students. At present four batches of MBBS are studying in the college. The batch with which we conducted our study is the III ${ }^{\text {rd }}$ batch of this college which entered this college in the year 2015. The total number of students admitted in this batch is 49. The number of girls in this batch is 29 and the number of boys is 20 . The students are basically from CG. state, but few of them are also from other states of India.

As the students have passed It MBBS and they have entered II $^{\text {nd }} \mathrm{MBBS}$, so they have a basic knowledge about the drugs, among them. This study was conducted to evaluate the self-medication practices with antibiotics among the second year medical students.

\section{MATERIALS AND METHODS}

\section{Study Setting}

This study was conducted in the Department of Pharmacology of (LSLAM, GMC). Students come for their theory classes in the morning from 8:30-9:30 am and then second class is from 9:30-10:30 am. This study was done after the second theory class was over.

\section{Study Design}

The participants were explained about what is the meaning of self-medication and how does it differ from routine prescription studies. An informed consent was taken from all students who participated in the study. Institutional Ethics Committee permission was taken before the start of the study.

A questionnaire containing 13 questions was designed keeping in view the knowledge and perception of the students. They were given 20 minutes to fill the questionnaire and they were told not to mention their identity i.e they were told not to write their names or roll number on the questionnaire.

The questionnaire contained questions pertaining to the patterns of self-medication with antibiotics, type of antibiotic used, source of antibiotic, health condition or disease state that lead to self-medication.

Data were collected and put into excel sheet and the collected data were analysed with graph pad.

\section{RESULTS}

The total number of second MBBS students in this batch is 49 . On the day when the study was conducted only 47 out of 49 students were present. All the students were between the age group of 19-21 years. Females outnumber males in this study as the total number of female students who participated in the study was 27 and only 20 were male students.

The most common indication for which Selfmedication was opted was fever with cough and cold (Figure.1) and the information about the antibiotic was obtained from a past prescription from a doctor where in the student has succumbed to the same type of infection in the past. Some students also suggested that they got information from their close relative or from their friends depending upon whose suggestion they took the antibiotics. Some also suggested that the information was obtained from the book, that was reliable and such as authentic information was used to treat them.(Figure 2)

The next question was related to the practise of Selfmedication in the past, for which some students replied that they had taken antibiotics in past with the help of previous prescription written by a practising physician, some of them responded that they never practised Selfmedication in the past.

The most common antibiotic that was used by most of the students was azithromycin, second most common antibiotic was ofloxacin/ciprofloxacin. Less common antibiotic used were cephalosporin, tetracycline, amoxicillin, nitrofurantoin etc.(Figure. 3)

Next question was about any other drug that was taken simultaneously along with the antibiotic, i.e. details about co-prescription. This also is very important to know as this check the prescribing ability of the students, whether they understand the gravity of the problem, or the condition from which they suffer and also involves the thinking capacity of students.

Another important point discussed in this questionnaire was regarding the period for which they took the aforesaid antibiotic. This suggests the rationality of use of antibiotics as prescribing for less than the standard duration might lead to development of resistance and this should be known to the so called future doctors as their effort in future can reduce or decrease the chances of developing antibiotic resistance. Many of 


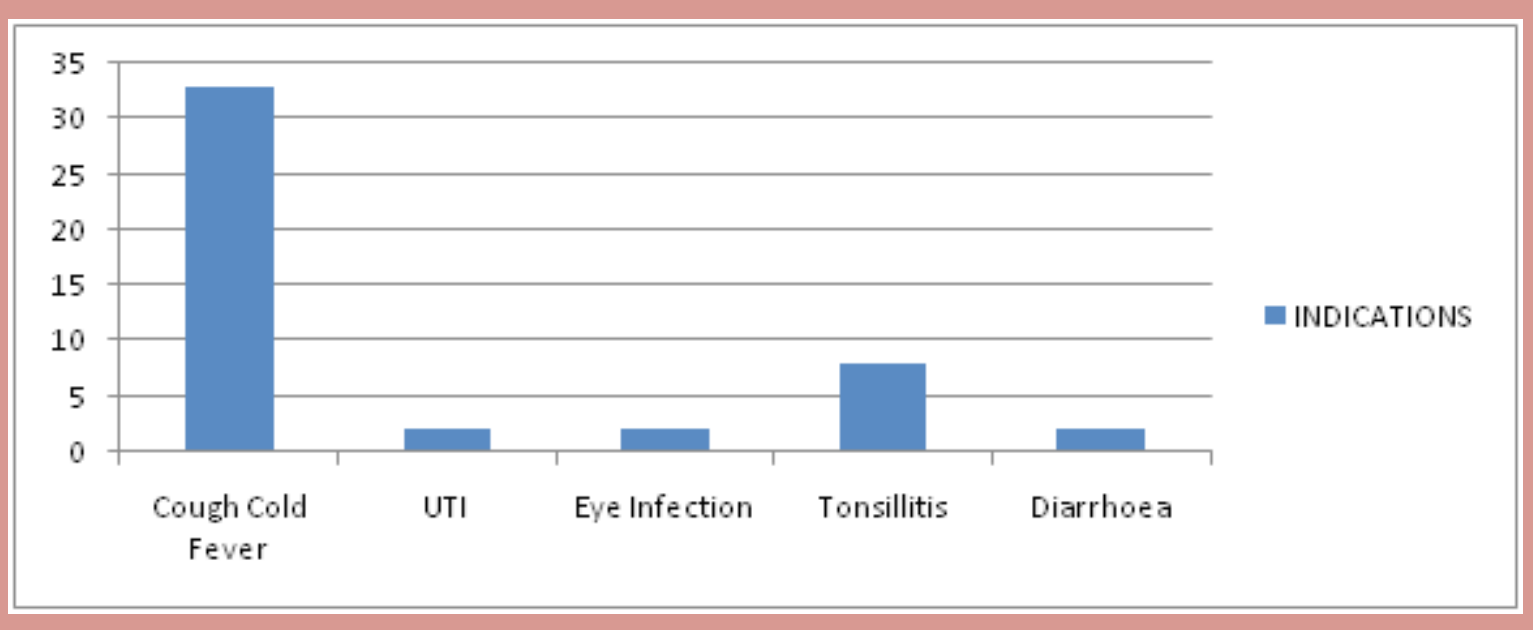

Figure 1 Figure 1: Most common indications for which Self-medication was practiced

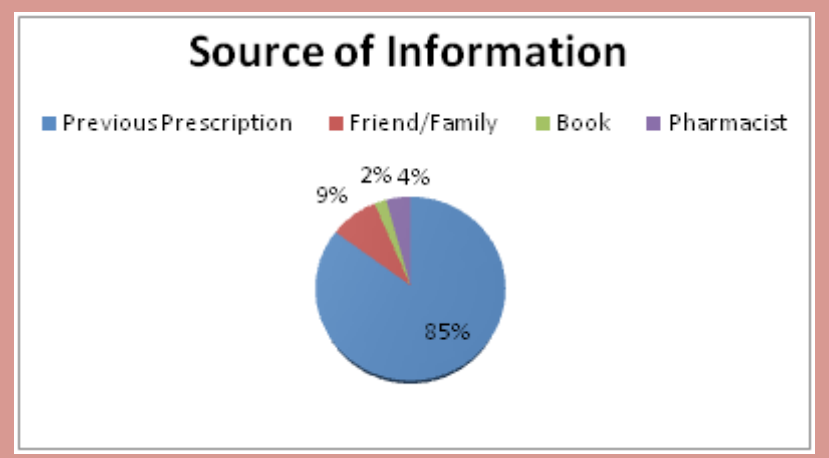

Figure 2: Various sources for the drugs of self medication practice

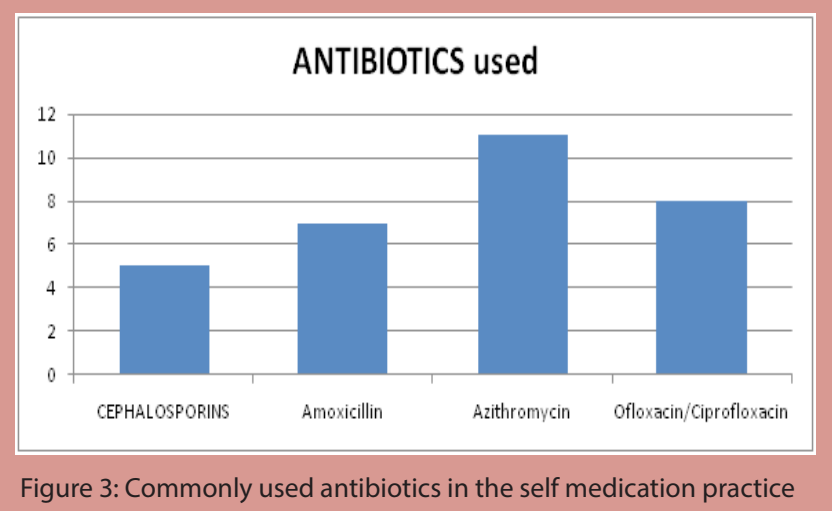

DISCUSSION

the students have written 3 days of treatment with the mentioned antibiotics which suggested that the thinking perspective and judgment based upon their knowledge is almost satisfactory. Some of the students have written that the antibiotic should be prescribed for 5-7 days which again is satisfactory at the student level. Two students have mentioned that the antibiotic should be taken only to the duration of one day, which is absolutely against the prevalent guidelines which suggested that this type of treatment with antibiotics can lead to development of resistance.

Last question was regarding the development of $A D R$ with the intake of antibiotic. Most of the students have mentioned that they developed no ADR following the intake of antibiotic. One student mentioned that with the use of erythromycin, she suffered from vomiting and vertigo for which she discontinued that antibiotic and did not took any other drug to control of ADR.
Prevalence of self-medication with antibiotics is very high in our study. Almost all the students who participated in the study agreed that sometime in the past they have taken one or the other antibiotic. This was in concordance with other studies which suggested high level of self-medication among medical undergraduates. ${ }^{[3-6]}$ Students in whom this study was done were not taught antibiotics (chemotherapy) at the time of study. Instead of not being taught the chapter on antimicrobials the students were quite aware of the use of this class of drugs i.e. the level of knowledge of these students is quite high as regards to the use of antimicrobials.

In our study it was seen that most common indication for which self-medication sought was cough, cold and fever. This was also seen in a study done on nursing students in a govt. medical college of West Bengal, ${ }^{[7]}$ similar in a study done on allopathic medical doctors 
in Karnataka ${ }^{[8]}$ and among the medical students in south India. ${ }^{[4]}$

The source of information about the use of antibiotic in our study was a previous prescription, which was similar in a study done on the community of Abu Dhabi, where in $56 \%$ of the respondent obtained information from a previous prescription by a doctor/dentists ${ }^{[9]}$ also it was $53.5 \%$ in another study done on medical UG in Karnataka. ${ }^{[10]}$

Antibiotic which was most commonly used by the students in our study was azithromycin or we can say that macrolide group was most commonly used followed by quinolone group, whereas other studies have mentioned that amoxicillin was the most commonly used antibiotic. ${ }^{(9)}$ In one study, it was seen that metronidazole was the most commonly prescribed antibiotic. ${ }^{[7]}$

Most of the students in our study mentioned correctly the duration for which the mentioned antibiotic should be taken. Most of them $(n=28)$ have written that the mentioned antibiotic should be taken for a period of 3 days when as 11 students mentioned that it should be taken for a period of 5 days, some students $(n=8)$ mentioned that it should be taken for less than 3 days. Surprisingly, even the junior second year students were well aware about the importance of completing the entire course of therapy. But their knowledge about the medicines for which completing course was inadequate. ${ }^{[11]}$

However in one study done by Shankar et al., it was seen that antimicrobials (AMA) were only taken for the proper duration in 4 of the 16 instances where they had been prescribed and the average duration for which an AMA was used was 2.78 days. $^{[12]}$

\section{LIMITATIONS OF THE STUDY}

Sample size used in our study was quite small, as the number of students taking admission in this college is only 50 per year. Anyhow this study could be extrapolated to general population and results can therefore be compared. Knowledge of the students was quite adequate inspite of being not taught the chapter related to antibiotic use.

This study can be compared with their senior counterparts and the level of knowledge and perception regarding the use of AMA can be seen.

\section{CONCLUSION}

There was a high level of self-medication with antibiotics in our study and this seems to be true as the medical students are quite aware about the prescribing trend as well as are updated as they come to second MBBS. But this high level of self-prescription seen is also having some disadvantages, as improper duration of use might lead to development of resistance, hence there is a need of a module to educate and aware the students about advantages of responsible self-medication and drawbacks of self-medication. ${ }^{[5]}$ Therefore as an optimistic approach "self-medication" is not always hazardous when one knows for what complaint which medicine is to be used. However, it is necessary to educate people for circumstances where they may self-medicate and when they must see a doctor even for apparently trivial complaint. ${ }^{[13]}$

\section{ACKNOWLEDGEMENT}

We are very much thankful to the students of second MBBS for their support and participation in this study. Also we would like to thank Dr. SP Singh (Statistician) of our Medical College for rendering help to carry out this project successfully.

\section{CONFLICTS OF INTEREST}

None declared

\section{REFERENCES}

1. Awad A, Eltayeb I, Matowe L. Self-medication with antibiotics and antimalarial in the community of Khartoum state, Sudan. J Pharm Sci 2005;8(2):326-31.

2. World Health Organization (2000). Guidelines for the regulatory assessment of Medicinal Products for use in self-medication. WHO/EDM/QSM/00.1

3. James H, Handu SS, Khalid AJ, Khaja A, Obtoom S, Sequeira RP. Evaluation of the knowledge, attitude and practice of selfmedication among first-year medical students. Med Princ Pract. 2006;15(14):270-5.

4. Badiger S, Kundapur R, Jain A, Kumar A, Patanashetty S, Thakolkaran N, et al. Self-medication patterns among medical students in south India. AMJ. 2012;5:(4):217-20.

5. Gyawali S, Shankar PR, Poudel PP, Saha A. Knowledge, Attitude and Practice of self-Medication among basic science undergraduates medical students in a medical school in western Nepal. JCDR. Dec. 2015:9(12);17-22.

6. Pandya RN, Jhaveri KS, Vyas FI, Patel VJ. Prevalence, pattern and perception of self-medication in medical students. IJBCP 2013;2(3):275-80.

7. Biswas S, Ghosh A, Mondal K, Dalui JR, Haldar M, Biswas S. Self-medication with antibiotics among undergraduate nursing 
students of a government medical college in Eastern India. IJPR. 2015: 5;(10);239-43.

8. Nalini GK. Self-medication among allopathic medical doctors in Karnataka, India. BJMP, 2010;(2):325.

9. Abasaeed A, Vleek J, Abuelkhair M, Kubera A. Self-medication with antibiotics by the community of Abu Dhabi Emirates. UAE. J infect Dev Ctries 2009;3(7):491-7.

10. Roopadevi HS, Kumar NSS, Pankaja R, Ramesh KN. Assignments of self-medication practices among undergraduate medical students at a tertiary care teaching hospital, Karnataka. IJSR. 2015;4:(8);58-60.
11. Sontakke SD, Bajait CS, Pimpalkhute SA, Jaiswal KM, Jaiswal SR. Comparative study of evaluation of self-medication practice in first and third year medical students. Int J Biol Med Res 2011;2(2):561-4.

12. Shankar PR, Partha P, Shenoy N. Self-medication and nondoctor prescription practices in Pokhara valley, Western Nepal: a questionnaire based study. BMC Family Practice. 2002;3(1):17.

13. Mumtaz $Y$, Jahangeer SMA, Mujtaba T, Zafar S, Adnan S. Selfmedication among university students of Karachi. JLUMHS. Sept.Dec. 2011. 10(3);102-5. 